\title{
Sensitivity to Perioperative Ischemia/Reperfusion Injury in Male and Female Donor Myocardium
}

\author{
M. SMETANA ${ }^{1}$, J. BESIK ${ }^{1}$, I. NETUKA ${ }^{1}$, J. MALY $^{1}$, J. MALUSKOVA $^{2}$, \\ A. LODEREROVA ${ }^{2}$, L. HOSKOVA ${ }^{3}$, J. FRANEKOVA ${ }^{4}$, E. POKORNA ${ }^{5}$, \\ J. PIRK ${ }^{1}$, O. SZARSZOI ${ }^{1}$
}

${ }^{1}$ Department of Cardiovascular Surgery, Institute for Clinical and Experimental Medicine, Prague, Czech Republic, ${ }^{2}$ Department of Pathology, Institute for Clinical and Experimental Medicine, Prague, Czech Republic, ${ }^{3}$ Department of Cardiology, Institute for Clinical and Experimental Medicine, Prague, Czech Republic, ${ }^{4}$ Department of Laboratory Methods, Institute for Clinical and Experimental Medicine, Prague, Czech Republic, ${ }^{5}$ Department of Transplant Surgery, Institute for Clinical and Experimental Medicine, Prague, Czech Republic

Received October 18, 2016

Accepted May 26, 2017

On-line September 22, 2017

\section{Summary}

Many functions of the cardiovascular apparatus are affected by gender. The aim of our study was find out whether markers of cell death present in the donor myocardium differ in male and female hearts. The study involved 81 patients undergoing heart transplantation from September 2010 to January 2013. Patients were divided into two groups: male allograft $(n=49)$, and female allograft $(n=32)$. Two types of myocardial cell death were analyzed. High-sensitive cardiac troponin $\mathrm{T}$ as a necrosis marker and protein bcl-2, caspase 3 and TUNEL as apoptosis markers were measured. We observed a significantly higher level of high-sensitive cardiac troponin $\mathrm{T}$ after correcting for predicted ventricular mass in female donors before transplantation as well as in the female allograft group after transplantation throughout the monitored period $(P=0.011)$. There were no differences in apoptosis markers (bcl-2, caspase 3 , TUNEL) between male and female hearts before transplantation. Both genders showed a significant increase of TUNEL-positive myocytes one week after transplantation without differences between the groups. Moreover, there were no differences in caspase 3 and bcl-2 expression between the two groups. Our results demonstrated the presence of necrotic and apoptotic cell death in human heart allografts. High-sensitive cardiac troponin $\mathrm{T}$ adjusted for predicted ventricular mass as a marker of myocardial necrosis was higher in female donors, and this gender difference was even more pronounced after transplantation.

\section{Key words}

Heart transplantation - Necrosis - Apoptosis - Sensitivity to ischemia

\section{Corresponding author}

J. Besik, Department of Cardiovascular Surgery, Institute for Clinical and Experimental Medicine, Vídeňská 1958/9, 14021 Prague 4, Czech Republic. Fax: (+420) 261081 362. E-mail: Josef.Besik@ikem.cz

\section{Introduction}

Heart transplantation has evolved into the treatment of choice for patients with end-stage heart failure. Nevertheless, donor hearts are subjected to different types of insults during the transplant procedure that exacerbate post-transplant cardiac ischemia/ reperfusion injury and decrease allografts survival including brain death, hypothermic storage, warm ischemia and finally reperfusion (Atkinson et al. 2013). From available data it is evident that male and female cardiovascular systems differ significantly in many characteristics under both physiological and pathological conditions. The majority of experimental studies confirm the clinical observations that the female heart is more resistant to ischemia/reperfusion injury (Ostadal et al. 
2009). On the other hand, several clinical studies have identified female donor sex as an independent predictor of recipient mortality after heart transplantation (Bryan et al. 1996, McCarthy et al. 1998, Solomon et al. 2004, Tsai et al. 2002). Female sex has been also shown to be a risk factor for greater severity of rejection (Mills et al. 1997) as well as recurrent rejection episodes (Kubo et al. 1995). Thus far it is not clear whether these differences are caused by genetic, hormonal or immunologic factors. Sex differences in susceptibility to ischemia/reperfusion injury have also been proposed (Zeier et al. 2002). However, the data comparing the tolerance of male and female allografts to ischemia during heart transplantation are not yet available. Therefore the aim of our prospective study was to find out whether cell death, necrosis and apoptosis-markers, present in the donor myocardium perioperatively differ in male and female hearts.

\section{Patients and Methods}

The prospective study involved 81 consecutive patients who underwent orthotopic heart transplantation at our institution from September 2010 to January 2013. Patients were divided into two groups according to donor gender: male allograft $(n=49)$ and female allograft $(n=32)$. The study was approved by the human research ethics committee of our institution and written informed consent was obtained from all patients enrolled in the study. All patients were treated according to the current guidelines for the management of heart failure and transplantation. The standard criteria accepted in our institution were used for donor selection. Myocardial protection was initiated with cardioplegic arrest, using St. Thomas crystalloid cardioplegia solution with bicarbonate $(1,500 \mathrm{ml}, \mathrm{pH} 7.4$, $\left.4-10{ }^{\circ} \mathrm{C}\right)$. Cardiac grafts were also stored in cold St. Thomas cardioplegia solution and transported on ice. Cold blood cardioplegia was administered at the beginning and then subsequently every 20 min during implantation.

The arterial blood sample used for high-sensitive cardiac troponin $\mathrm{T}$ (hs-cTnT) detection was taken from the donor before the pericardium was opened and from the recipient before sternotomy, two hours after transplantation, on the first postoperative day (POD, $24 \mathrm{~h}$ after cross-clamp removal), third POD, and one week after surgery. Each sample was centrifuged and the serum stored at $-70{ }^{\circ} \mathrm{C}$ until the study was completed. Detection of hs-cTnT was performed using electrochemiluminescence immunoassay ( $\mathrm{T}$ hs STAT, Cobas e411, Roche Diagnostics GmbH, Mannheim, Germany) according to the manufacturer's recommendations in an accredited laboratory. The limit of detection was $5 \mathrm{ng} / \mathrm{l}$ and limit of quantification $13 \mathrm{ng} / \mathrm{l}$. There were no samples below the detection limit.

It is well known that the size and weight of female and male hearts significantly differ (Ostadal et al. 2009). Since weighing the hearts during transplantation was difficult, the mass of both ventricles was calculated. For the left ventricle we used the following equation: predicted left ventricular mass $(\mathrm{g})=\mathrm{a} \cdot \operatorname{Height}^{0.54}(\mathrm{~m})$. Weight $^{0.61}(\mathrm{~kg})$, where $a=6.82$ for women and 8.25 for men. For the right ventricle we used: predicted right ventricular mass $(\mathrm{g})=\mathrm{a} \cdot \operatorname{Age}^{-0.32}$ (years) $\operatorname{Height}^{1.135}(\mathrm{~m}) \cdot$ Weight $^{0.315}(\mathrm{~kg})$, where $a=10.59$ for women and 11.25 for men (Reed et al. 2014).

Apoptosis was assessed from biopsy specimens taken from the right ventricle prior to collection of the donor graft, twenty minutes after cross-clamp release and one week after transplantation. The samples were taken by endomyocardial biopsy (EMB) from the right ventricle. The biopsy specimens were fixed in $10 \%$ formalin solution, embedded in paraffin, cut at $4 \mu \mathrm{m}$ and stained with hematoxylin-eosin (H\&E). Immunohistochemical detection of caspase 3 (clone JHM 62, Novocastra, Leica Microsystems, UK) was performed on $4 \mu \mathrm{m}$ thick sections of paraffin-embedded tissues using the VENTANA BenchMark ULTRA system (Tucson, AZ, USA) with the ultraView Universal DAB Detection Kit. Immunohistochemical detection of bcl-2 (clone 3.1, Novocastra, Leica Microsystems, UK) was performed on $4 \mu \mathrm{m}$ thick paraffin sections using a two-step indirect method. Apoptosis detection was performed on $4 \mu \mathrm{m}$ thick paraffin sections using a TUNEL peroxidase apoptosis detection kit (Roche Diagnostics GmbH, Germany) according to the manufacturer's instructions. In all immunohistochemical methods (caspase 3, bcl-2) and TUNEL, the slides were observed by light microscope (Olympus BX41). The numbers of positive cells were counted in 10 high power fields (HPF) and then the average number of positive cells per 1 HPF was used for statistical analysis.

\section{Statistical analysis}

The results were expressed as mean \pm standard error of mean (SEM); non-Gaussian distributed variables were expressed as median and range. Differences in expression of bcl-2, caspase 3 and TUNEL between the female and male donors were compared using a two-sample Wilcoxon non-parametric test; the time comparison among the groups was performed using the 
Wilcoxon signed rank test with the Bonferroni correction. After normalization by logarithmic transformation, differences in hs-cTnT levels between the groups were compared using repeated-measures analysis of variances (ANOVA) with one grouping factor. The Fischer exact test and t-test were used to test for group differences in the qualitative data. All tests were two-sided and were assumed as statistically significant when $\mathrm{P}<0.05$.

\section{Results}

There were no differences among the groups in regard to baseline demographics except for cause of death among donors and the occurrence of heart valve disease in recipients (Table 1). The mean ischemic time was $146 \pm 7.8 \mathrm{~min}$ for the group with male allografts and $141 \pm 9$ min for the group with female allografts.

Table 1. Recipient, donor and operative baseline characteristics.

\begin{tabular}{|c|c|c|c|}
\hline & $\begin{array}{c}\text { Male donor } \\
\qquad(n=49)\end{array}$ & $\begin{array}{l}\text { Female donor } \\
\qquad(n=32)\end{array}$ & $P$ value \\
\hline \multicolumn{4}{|l|}{ Recipient parameters } \\
\hline Age & $51.8 \pm 1.8$ & $49.8 \pm 2.7$ & 0.50 \\
\hline Body mass index & $25.1 \pm 0.5$ & $24.5 \pm 0.7$ & 0.44 \\
\hline Diabetes mellitus & $5(10)$ & $7(21)$ & 0.15 \\
\hline Hypertension & $7(14)$ & $4(13)$ & 0.45 \\
\hline Serum creatinine $(\mu \mathrm{mol} / \mathrm{l})$ & $103.1 \pm 3.7$ & $95.65 \pm 6.00$ & 0.27 \\
\hline Ischemic cardiomyopathy & $18(37)$ & $9(28)$ & 0.42 \\
\hline Dilated cardiomyopathy & $29(59)$ & $15(47)$ & 0.28 \\
\hline Valve heart disease and other & $2(4)$ & $8(25)$ & 0.005 \\
\hline Smoker: current or former & $4(8)$ & $3(9)$ & 0.59 \\
\hline Pre-operative inotropes & $11(22)$ & $7(22)$ & 0.97 \\
\hline Pre-operative mechanical circulatory support & $19(39)$ & $11(34)$ & 0.69 \\
\hline \multicolumn{4}{|l|}{ Donor parameters } \\
\hline Age & $39.6 \pm 1.7$ & $42.3 \pm 2.7$ & 0.38 \\
\hline Body mass index & $26.5 \pm 0.6$ & $25.0 \pm 0.7$ & 0.11 \\
\hline Diabetes mellitus & 0 & 0 & 0.21 \\
\hline Hypertension & $7(14)$ & $6(19)$ & 0.59 \\
\hline Left ventricular ejection fraction (\%) & $63.4 \pm 0.7$ & $64.5 \pm 1.3$ & 0.45 \\
\hline Smoker: current or former & $4(8)$ & $2(6)$ & 0.71 \\
\hline \multicolumn{4}{|l|}{ Cause of death } \\
\hline Subarachnoid bleeding & $9(18)$ & $9(28)$ & 0.4129 \\
\hline Intracerebral bleeding & $5(10)$ & $13(40)$ & 0.0022 \\
\hline Craniocerebral trauma & $25(51)$ & $8(25)$ & 0.0198 \\
\hline Others & $10(20)$ & $2(6)$ & 0.08 \\
\hline Donor inotropes & $42(86)$ & $25(78)$ & 0.29 \\
\hline Ischemic time & $146.0 \pm 7.8$ & $141.1 \pm 9.0$ & 0.70 \\
\hline
\end{tabular}

Continuous data are shown as mean \pm standard deviation and categoric data as number (\%).

Before transplantation, the hs-cTnT level adjusted for $10 \mathrm{~g}$ of predicted ventricular mass was significantly higher in female donors $(\mathrm{P}=0.025$, Fig. 1$)$. There were no differences in apoptosis markers (bcl-2, caspase 3, TUNEL) between male and female hearts.

After transplantation we observed significantly higher levels of hs-cTnT adjusted for $10 \mathrm{~g}$ of predicted ventricular mass in the female allograft group throughout the monitored period ( $\mathrm{P}=0.011)$, with the maximum on the first postoperative day (Fig. 2).

We observed a significantly increased number of TUNEL-positive myocytes in response to perioperative 
ischemia in both genders one week after transplantation compared to the pre-transplant levels (males: $19.2 \pm 1.6 \mathrm{vs}$. $4.4 \pm 0.6$; females $20.7 \pm 1.9$ vs. $8.7 \pm 1.9, \mathrm{P}<0.001$ ); in this respect there were no differences between male and female allografts (Fig. 3). In the post-transplantation period we did not find any differences in caspase 3 or bcl-2 expression between the two groups (Figs 4 and 5).
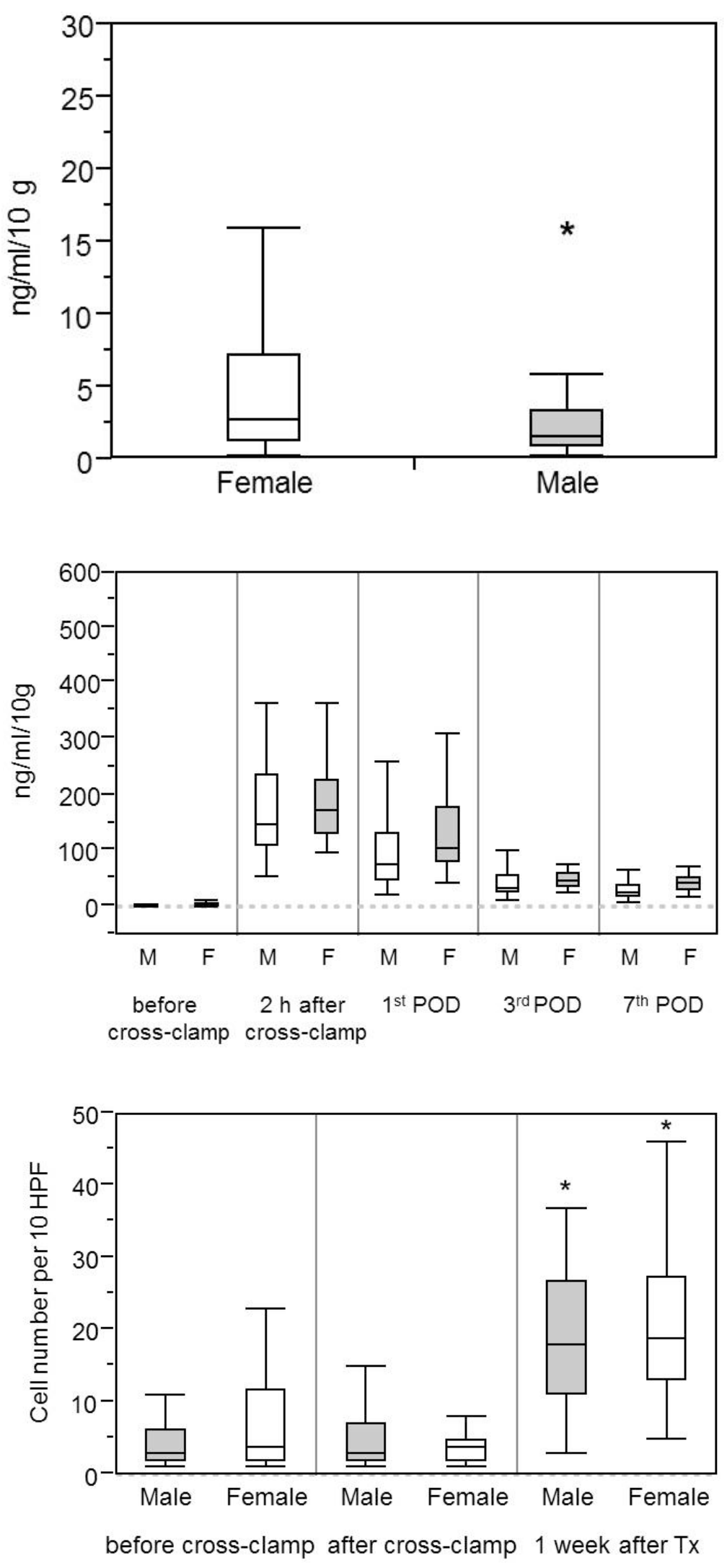

Fig. 1. High-sensitive cardiac troponin $T$ serum level adjusted for $10 \mathrm{~g}$ of predicted ventricular mass in male $(n=49)$ and female $(n=32)$ donors. Values are expressed as median and range; $* \mathrm{P}<0.05$ male vs. female.
Fig. 2. High-sensitive cardiac troponin $T$ serum level adjusted for $10 \mathrm{~g}$ of predicted ventricular mass in group with male $(n=49)$ and female $(n=32)$ allografts after transplantation. Values are expressed as median and range; male group vs. female group significant throughout the monitored period $(P=0.011)$.

Fig. 3. TUNEL positive cells in 10 high power fields (HPF) in the myocardium of patients with male $(n=49)$ and female $(n=32)$ allografts. Values are expressed as median and range; $* P<0.05$ vs. pre-transplant corresponding group. 

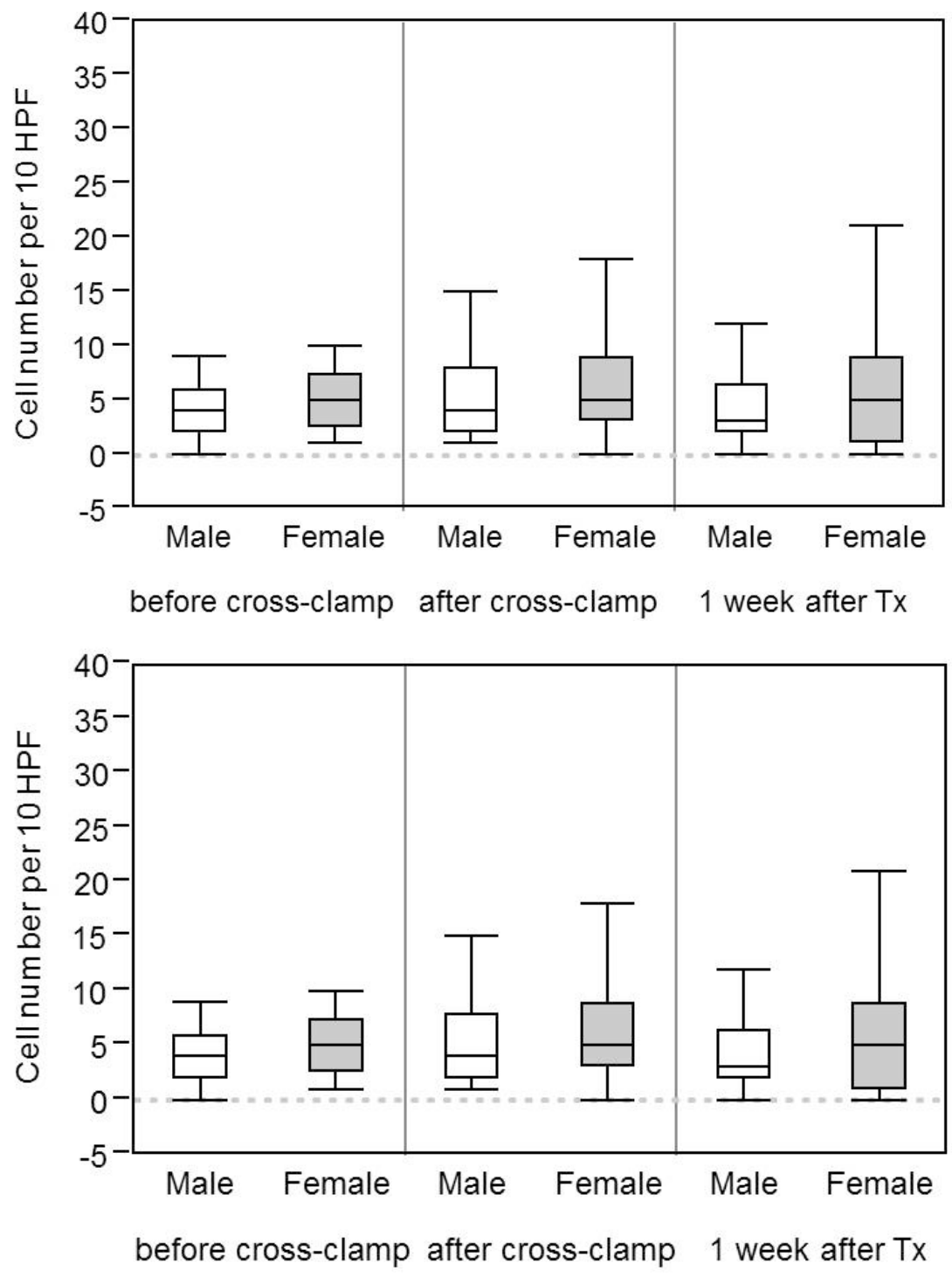

Fig. 4. Detection of bcl-2 positive cells in 10 high power fields (HPF) in myocardium of patients with male $(n=49)$ and female $(n=32)$ allografts. Values are expressed as median and range.

Fig. 5. Detection of caspase 3 positive cells in 10 high power fields (HPF) in myocardium of patients with male $(n=49)$ and female $(n=32)$ allografts. Values are expressed as median and range.

\section{Discussion}

Our results show that when adjusted for predicted ventricular mass, hs-cTnT, a novel marker of minor myocardial necrosis associated with ischemia/ reperfusion injury, was significantly higher in female donors before transplantation. After surgery, this gender difference was even more pronounced throughout the monitored period. In our study we found that both genders showed a significantly increased number of TUNEL positive myocytes in response to perioperative ischemia/reperfusion injury one week after transplantation. There were no differences in apoptosis in male and female hearts found by TUNEL assay or bcl-2 and caspase 3 expression.

During the transplant procedure, donor hearts are subjected to different types of insults that can exacerbate post-transplant myocardial ischemia/reperfusion injury and decrease allograft survival, including destructive processes during brain death. Neurogenic stunned myocardium (NSM) is defined as myocardial injury and dysfunction found after various types of acute brain injury as a result of an imbalance in the autonomic nervous system (Mierzewska-Schmidt and Gawecka 2015). NSM has commonly been described in patients with subarachnoid hemorrhage (SAH). Cardiac troponin T is a preferred biomarker for the diagnosis of cardiac damage and its increase correlates with the extent of left ventricular dysfunction and the severity of the neurologic condition (Zhang et al. 2015). There was no difference in $\mathrm{SAH}$ incidence in our donor groups. However, NSM has been observed in patients with ischemic stroke, craniocerebral trauma, encephalitis, acute hydrocephalus and other acute central nervous system injuries (Mierzewska-Schmidt and Gawecka 2015). We have analyzed hs-cTnT serum concentrations and causes of 
brain death in donors and found no association between the cause of brain death and hs-cTnT concentration in our study group. We believe that brain death is generally the most extensive brain injury, irrespective of its cause.

There are many reasons to believe that donor sex may play an important role in outcomes after heart transplantation. Several early studies identified female donor sex as an independent predictor of recipient mortality after heart transplantation (Bryan et al. 1996, McCarthy et al. 1998, Solomon et al. 2004, Tsai et al. 2002, Khush et al. 2012). One of the reasons for this fact may be the lower mass of the female heart. Female hearts have about 15-30\% lower mass than male hearts, which is primarily due to differing physical constitutions; however, relative heart mass is also significantly lower in females than in males (Ostadal et al. 2009). Moreover, relative left ventricular mass is also lower in females than in males, even after corrections for age and blood pressure (Hinderliter et al. 1992). Even when respecting mass and constitutional similarities in selecting a suitable donor, this fact may play a significant role in the adaptation and subsequent long-term function of a female donor heart in the body of a male recipient (Al-Khaldi et al. 2006).

The transplant literature also discusses genetic and hormonal factors that may at least partially explain these differences. Adult males lose approximately 64 million myocytes every year with compensatory hypertrophy of the remaining cardiocytes, whereas the number of myocytes in females practically remain unchanged throughout their lives (Olivetti et al. 1995). If this determined by hormones, it may be assumed that following transplantation of a female heart into a male body, similar changes may also occur in the transplanted organ with the same or even greater intensity as the heart is not only stripped of the protective influence of female sex hormones, but also exposed to the effects of male sex hormones (Al-Khaldi et al. 2006).

Lastly but importantly, the literature points to the cardiac muscle responding differently to the lack of oxygen during cold ischemia depending on the donor's gender. This relates not only ischemia/reperfusion injury to the donor heart during transplantation, which likely contributes to the development of primary graft failure (Iyer et al. 2011), but also ischemia-induced changes that result in damage to the function of the transplanted organ over time, as is similar in kidney transplants (Zeier et al. 2002). On the other hand, most experimental observations have confirmed increased resistance of the female myocardium to ischemia/reperfusion injury (Ostadal et al. 2009, Lagranha et al. 2010, Kolar and Ostadal 2013). It should be noted that experimental studies were performed on anesthetized animals or on hearts from animals immediately after decapitation; i.e. animals that were not exposed to destructive processes associated with brain death. Similarly, clinical studies include patients with acute myocardial infarction, after percutaneous interventions or cardiac surgery, i.e. in subjects without brain death. Heart transplantation is the only situation in which we encounter a damaged heart that has undergone the pathophysiological changes occurring during brain death. Whereas the increased plasma concentration of cardiac troponin $\mathrm{T}$ (calculated per unit of weight of the heart tissue) is present in female donors already before heart harvesting, we can assume different donor graft damage during brain death.

In response to prolonged ischemia during heart transplantation, cardiomyocytes may develop cell edema, apoptosis and necrosis. Cardiac troponin is an established marker of cardiac necrosis with unchallenged myocardial tissue specificity and is routinely used for therapeutic decision-making in acute coronary syndromes. New high-sensitivity troponin assays have recently been developed with $65-100 \%$ of measurable troponin concentrations below the 99th percentile of the apparently healthy population (Giannitsis and Katus 2009). There are only limited studies investigating the use of hs-cTnT assay during heart transplant procedures. Erbel et al. (2013) tested the predictive power of hs-cTnT blood levels soon after heart transplantation in 141 allograft recipients. They demonstrated that patients who died within the first year after transplantation had significantly higher median hs-cTnT serum levels six weeks after transplantation. In multivariate analysis, hs-cTnT serum levels six weeks after transplantation emerged as an independent predictor for first-year mortality. Determining hs-cTnT or high-sensitive cardiac troponin I (hs-cTnI) may also be useful for excluding acute rejection after transplantation as was described in the studies of Méndez et al. (2014), Patel et al. (2014) and Ahn et al. (2015). Nevertheless, gender differences in tolerance to ischemia/reperfusion injury in transplanted hearts have not been evaluated so far. Our results show that female hearts seem to be more vulnerable to ischemia/reperfusion injury during heart transplantation compared to male hearts, and this fact may contribute to poorer post-transplantation results when a female allograft is used. 
Besides cardiomyocyte necrosis during the transplant procedure, excessive programmed cell death is also thought to play an important role in this ischemia/reperfusion-associated injury. There are only limited studies investigating apoptosis in the human myocardium before or after heart transplantation. Molecular evidence for apoptosis has been previously investigated in transplanted hearts and in hearts not accepted for transplantation. Birks et al. (2000) demonstrated that caspases were elevated in dysfunctional donor hearts compared to hearts with good ventricular function. Significantly higher expression levels of genes involved in apoptosis (BAX, caspase 3 and FAS) in donor hearts compared with control patients were shown also in a study by Stoica et al. (2003). In a prospective study by Chalabreysse et al. (2004), apoptosis was determined from right ventricle biopsies from brain-dead donors. The authors confirmed that brain death induces apoptosis in the right ventricle, but a high apoptotic index does not correlate with subsequent myocardial function in the grafted heart and does not predict myocardial dysfunction during the first postoperative year. An association between increased expression of pro-apoptotic markers and primary graft dysfunction in cardiac allograft recipients was documented in a study by Marasco et al. (2014).

The most commonly used technique to detect apoptosis in tissue sections is terminal deoxynucleotidyl transferase dUTP nick and labeling (TUNEL), an enzymatic reaction that labels with modified nucleotides the free 3'-hydroxy ends of fragmented DNA, characteristic of the apoptotic process. Nevertheless, DNA fragmentation is a relatively late event in the apoptosis process. This does not exclude the possibility that some cardiac myocytes after ischemia/reperfusion injury have already initiated the apoptotic process, although undetectable by TUNEL assay. In order to reduce the possibility of under-rating the incidence of apoptosis, the TUNNEL was complemented by immunohistochemical detection of the pro-apoptotic protein caspase 3 and anti-apoptotic protein bcl-2, which enabled molecular identification of changes occurring during apoptosis earlier than DNA fragmentation (Thornberry and Lazebnik 1998, Scarabelli and Gottlieb 2004). We observed significantly increased number of TUNEL-positive myocytes in both genders one week after transplantation.

In conclusion, our results demonstrated the presence of necrotic and apoptotic cell death in human heart allografts during transplant-related ischemia/ reperfusion injury. To our knowledge, gender differences in tolerance to perioperative ischemia/reperfusion injury in human transplanted hearts have not been demonstrated previously. The results from our study show that female hearts seem to be more vulnerable to ischemia/ reperfusion injury during heart transplantation than male hearts. Since the level of hs-cTnT adjusted for $10 \mathrm{~g}$ of predicted ventricular mass was significantly higher in female donors before donor heart harvesting, we can speculate about different and possibly gender-dependent heart damage during brain death. Therefore, more detailed investigations of possible gender differences in cardiac injury during brain death are required.

\section{Conflict of Interest}

There is no conflict of interest.

\section{Acknowledgements}

This study was supported by the Internal Grant Agency of the Ministry of Health of the Czech Republic No. NT/11269-5.

\section{References}

AHN KT, CHOI JO, LEE GY, PARK HD, JEON ES: Usefulness of high-sensitivity troponin I for the monitoring of subclinical acute cellular rejection after cardiac transplantation. Transplant Proc 47: 504-510, 2015.

AL-KHALDI A, OYER PE, ROBBINS RC: Outcome analysis of donor gender in heart transplantation. $J$ Heart Lung Transplant 25: 461-468, 2006.

ATKINSON C, FLOERCHINGER B, QIAO F, CASEY S, WILLIAMSON T, MOSELEY E, STOICA S, GODDARD M, GE X, TULLIUS SG, TOMLINSON S: Donor brain death exacerbates complement-dependent ischemia/reperfusion injury in transplanted hearts. Circulation 127: 1290-1299, 2013.

BIRKS EJ, YACOUB MH, BURTON PS, OWEN V, POMERANCE A, O'HALLORAN A, BANNER NR, KHAGHANI A, LATIF N: Activation of apoptotic and inflammatory pathways in dysfunctional donor hearts. Transplantation 70: 1498-1506, 2000. 
BRYAN CF, MITCHELL SI, BORKON AM, CURTIS J, DEMMY T, ESTEP TH, MORAN J: Influence of donor gender on patient mortality after heart transplantation. Transplant Proc 28: 149-151, 1996.

CHALABREYSSE L, LEROUX C, OBADIA JF, GREENLAND T, THIVOLET-BEJUI F, MORNEX JF: Apoptosis in right-ventricle biopsy is not predictive of graft survival. Transpl Int 17: 362-365, 2004.

ERBEL C, TASKIN R, DOESCH A, DENGLER TJ, WANGLER S, AKHAVANPOOR M, RUHPARWAR A, GIANNITSIS E, KATUS HA, GLEISSNER CA: High-sensitive troponin T measurements early after heart transplantation predict short- and long-term survival. Transpl Int 26: 267-272, 2013.

GIANNITSIS E, KATUS HA: Troponins and high-sensitivity troponins as markers of necrosis in CAD and heart failure. Herz 34: 600-606, 2009.

HINDERLITER AL, LIGHT KC, WILLIS PW: Gender differences in left ventricular structure and function in young adults with normal or marginally elevated blood pressure. Am J Hypertens 5: 32-36, 1992.

IYER A, KUMARASINGHE G, HICKS M, WATSON A, GAO L, DOYLE A, KEOGH A, KOTLYAR E, HAYWARD C, DHITAL K, GRANGER E, JANSZ P, PYE R, SPRATT P, MACDONALD PS: Primary graft failure after heart transplantation. J Transplant 2011: 175768, 2011.

KHUSH KK, KUBO JT, DESAI M: Influence of donor and recipient sex mismatch on heart transplant outcomes: analysis of the International Society for Heart and Lung Transplantation Registry. J Heart Lung Transplant 31: 459-466, 2012.

KOLAR F, OSTADAL B: Sex differences in cardiovascular function. Acta Physiol (Oxf) 207: 584-587, 2013.

KUBO SH, NAFTEL DC, MILLS RM JR, O'DONNELL J, RODEHEFFER RJ, CINTRON GB, KENZORA JL, BOURGE RC, KIRKLIN JK: Risk factors for late recurrent rejection after heart transplantation: a multiinstitutional, multivariable analysis. Cardiac Transplant Research Database Group. J Heart Lung Transplant 14: 409-418, 1995.

LAGRANHA CJ, DESCHAMPS A, APONTE A, STEENBERGEN C, MURPHY E: Sex differences in the phosphorylation of mitochondrial proteins result in reduced production of reactive oxygen species and cardioprotection in females. Circ Res 106: 1681-1691, 2010.

MARASCO SF, SHEERAN FL, CHAUDHURI K, VALE M, BAILEY M, PEPE S: Molecular markers of programmed cell death in donor hearts before transplantation. J Heart Lung Transplant 33: 185-193, 2014.

MCCARTHY PM, MASSAD MG, COOK DJ, SMEDIRA NG, KASIRAJAN V, GOORMASTIC M, HOERCHER K, YOUNG JB: Risk factors for death after heart transplantation: does a single-center experience correlate with multicenter registries? Ann Thorac Surg 65: 1574-1578, 1998.

MÉNDEZ AB, CARDONA M, ORDÓÑEZ-LLANOS J, MIRABET S, PEREZ-VILLA F, ROIG E: Predictive value of high-sensitive troponin $\mathrm{T}$ to rule out acute rejection after heart transplantation. Rev Esp Cardiol 67: 775-776, 2014.

MIERZEWSKA-SCHMIDT M, GAWECKA A: Neurogenic stunned myocardium - do we consider this diagnosis in patients with acute central nervous system injury and acute heart failure? Anaesthesiol Intensive Ther 47: 175-180, 2015.

MILLS RM, NAFTEL DC, KIRKLIN JK, VAN BAKEL AB, JASKI BE, MASSIN EK, EISEN HJ, LEE FA, FISHBEIN DP, BOURGE RC: Heart transplant rejection with hemodynamic compromise: a multiinstitutional study of the role of endomyocardial cellular infiltrate. Cardiac Transplant Research Database. J Heart Lung Transplant 16: 813-821, 1997.

OLIVETTI G, GIORDANO G, CORRADI D, MELISSARI M, LAGRASTA C, GAMBERT SR, ANVERSA P: Gender differences and aging: effects on the human heart. J Am Coll Cardiol 26: 1068-1079, 1995.

OSTADAL B, NETUKA I, MALY J, BESIK J, OSTADALOVA I: Gender differences in cardiac ischemic injury and protection-experimental aspects. Exp Biol Med (Maywood) 234: 1011-1019, 2009.

PATEL PC, HILL DA, AYERS CR, LAVINGIA B, KAISER P, DYER AK, BARNES AP, THIBODEAU JT, MISHKIN JD, MAMMEN PP, MARKHAM DW, STASTNY P, RING WS, DE LEMOS JA, DRAZNER MH: High-sensitivity cardiac troponin I assay to screen for acute rejection in patients with heart transplant. Circ Heart Fail 7: 463-469, 2014. 
REED RM, NETZER G, HUNSICKER L, MITCHELL BD, RAJAGOPAL K, SCHARF S, EBERLEIN M: Cardiac size and sex-matching in heart transplantation: size matters in matters of sex and the heart. JACC Heart Fail 2: 73-83, 2014.

SCARABELLI TM, GOTTLIEB RA: Functional and clinical repercussions of myocyte apoptosis in the multifaceted damage by ischemia/reperfusion injury: old and new concepts after 10 years of contributions. Cell Death Differ 11: 144-152, 2004.

SOLOMON NA, MCGIVEN JR, ALISON PM, RUYGROK PN, HAYDOCK DA, COVERDALE HA, WEST TM: Changing donor and recipient demographics in a heart transplantation program: influence on early outcome. Ann Thorac Surg 77: 2096-2102, 2004.

STOICA SC, SATCHITHANANDA DK, ATKINSON C, CHARMAN S, GODDARD M, LARGE SR: Heat shock protein, inducible nitric oxide synthase and apoptotic markers in the acute phase of human cardiac transplantation. Eur J Cardiothorac Surg 24: 932-939, 2003.

THORNBERRY NA, LAZEBNIK Y: Caspases: enemies within. Science 281: 1312-1316, 1998.

TSAI FC, MARELLI D, BRESSON J, GJERTSON D, KERMANI R, ARDEHALI A, ESMAILIAN F, HAMILTON M, FONAROW GC, MORIGUCHI J, PLUNKETT M, HAGE A, TRAN J, KOBASHIGAWA JA, LAKS H: Recent trends in early outcome of adult patients after heart transplantation: a single-institution review of 251 transplants using standard donor organs. Am J Transplant 2: 539-545, 2002.

ZEIER M, DÖHLER B, OPELZ G, RITZ E: The effect of donor gender on graft survival. J Am Soc Nephrol 13: 2570-2576, 2002.

ZHANG L, WANG Z, QI S: Cardiac troponin elevation and outcome after subarachnoid hemorrhage: a systemic review and meta-analysis. J Stroke Cerebrovasc Dis 24: 2375-2384, 2015. 